speculation, confusion, and often misinformation. This can undermine confidence in the quality and dependability of cross-border education provision and impedes the analysis needed to underpin solid policy and regulatory frameworks.

\section{ISSUES AND IMPLICATIONS}

The national-level issues related to registration and licensing of cross-border providers, quality assurance, accreditation and recognition of qualifications affect individual providers and, especially, higher education institutions. The quality of academic programs starts with the provider delivering the program. Most higher education institutions employ adequate quality assurance procedures for domestic delivery but not necessarily for all the aspects of cross-border delivery. Working cross-culturally in a foreign regulatory environment and, potentially, with a partner can raise new issues-including academic entry requirements, student examination and assessment procedures, workload, delivery modes, adaptation of the curriculum, quality assurance of teaching, academic and sociocultural support for students, title and level of award, and others. Quality issues also need to be balanced with the financial investment and return to the source provider. Intellectual property ownership, choice of partners, division of responsibilities, academic and business risk assessments, and internal and external approval processes constitute only some of the issues the higher education institutions need to resolve.

The growth in the volume, scope, and dimensions of crossborder education may provide increased access and promote innovation and responsiveness of higher education, but these developments also bring new challenges and unexpected consequences. The current realities include the fact that unrecognized and rogue cross-border providers are active, that much

\section{It is important to acknowledge the huge poten- tial of cross-border education but not at the expense of academic quality and integrity.}

of the latest cross-border education is driven by commercial interests, and that mechanisms to recognize qualifications and ensure quality of the academic courses and programs are still not in place in many countries. These realities present major challenges to the education sector. It is important to acknowledge the huge potential of cross-border education but not at the expense of academic quality and integrity. Higher education is not the only sector that needs to look at ways to guide, monitor, and regulate the movement of education programs and providers. It needs to work in close cooperation with other sectors and to play a pivotal role in ensuring that cross-border education reflects and helps to meet individual countries' educational goals, culture, priorities, and policies.

\section{International Students at Indian Universities}

\section{Veena Bhalla}

Veena Bhalla is on the staff of the Association of Indian Universities. Address: 16, Comrade Indrajit Gupta Marg. New Delhi 110 002, India. Email:aiusis@yahoo.co.in.

$\mathrm{T}^{\mathrm{n}}$ ransnational movement of students is obviously the most visible and, perhaps, most significant manifestation of the internationalization of higher education. Since the early I990s the number of students crossing their national borders for acquiring knowledge and skills has steadily increased. The number of students entering developed countries has shown a considerable rise. Unfortunately, this has not happened in the case of India, which has the third-largest higher education system in the world and, therefore, is a potential exporter or provider of education, at least to the Third World.

Presently, international students from about 125 countries are pursuing various undergraduate, postgraduate, and research programs in India at recognized universities and institutions. The countries that provide the international students can be grouped into two categories: first, developed countries that are technologically advanced and economically strong and have good facilities for higher education and training (e.g., the United States, United Kingdom, Canada, Australia, countries of the European Union, and Japan); and second, the less-developed and developing countries that have limited facilities for education - not only in professional fields such as engineering, medicine, and management-but also in science, humanities, social sciences, commerce, and law.

Data collected by the Association of Indian Universities over the period 1992-I993 to 2003-2004 suggest the number of international students coming to India steadily increased during the first half of the I990s, with a peak of over 13,000 being achieved in I993-I994. Subsequently there was a steady decrease, with a marked fall occurring in 1996-I997; by the end of the millennium the number had halved. This trend was probably due to the fact that while many developed countries, and especially the United Kingdom and Australia, were aggressively marketing their educational ware, India was inactive in this regard. However, the number of international students increased during 200I-2002, after India adopted a more positive approach, possibly suggesting a reversal of the trend.

More than 95 percent of international students in India come from the developing countries of Asia and Africa. The countries that sent the most students in 2003-2004 are Malaysia, Nepal, Iran, and Kenya (about 500 each), followed by Mauritius, Sri Lanka, the United States, and Ethiopia (over 300 each). Significantly, during 2003-2004 there has been an increase in the number of students from East Asia, the Middle East, South and Central Asia, Southeast Asia, northern 
Europe, and North America. The largest number of students are from South and Central Asia $(2, \mathrm{IO} 2)$ followed by East Africa $(\mathrm{I}, 465)$. The countries that sent increased numbers of students in 2003-2004 include Bahrain, Kuwait, Oman, Saudi Arabia, the United Arab Emirates, Iran, Malaysia, Vietnam, Sudan, Ghana, Ethiopia, Mauritius, Canada, and the United States.

The same period (2003-2004) has seen a decrease in the number of students from North Korea, Syria, Yemen, Bangladesh, Bhutan, Nepal, Sri Lanka, Thailand, Eritrea, Kenya, Somalia, Tanzania, and Uganda. In the same year, the largest number of students came from Malaysia (806). In 2003-2004, the largest number attended the Manipal Academy of Higher Education (2,03I), followed by the University of Pune (I,4IG) and the University of Delhi (I,077).

International students prefer to join educational institutions located in metropolitan cities like Delhi, Mumbai, Chennai, and Pune. They join colleges located in smaller towns only for professional programs. As is to be expected, the international student population in India is not equally distributed over the country or in the various disciplines. Students prefer the western (especially Maharashtra) and southern parts of India. This is due to more congenial social and cultural environments.

To make Indian universities more attractive to international students will require a variety of improvements. Indian universities must take steps to provide better infrastructure and facilities to international students. The country's academic structure needs to "internationalize" the curricula and become more flexible. The University Grants Commission is promoting the export of education through its Committee for the Promotion of Indian Higher Education Abroad. Significantly, at this point the private universities and colleges are the ones making efforts to attract students by providing good infrastructure and other facilities.

\section{Foreign Universities in India: Market-Driven New Directions}

\section{Sudhanshu Bhushan}

Sudhanshu Bhushan is senior fellow and head of the Higher Education Unit, National Institute of Educational Planning and Administration, $17 B$ Sri Aurobindo Marg, New Delhi 110 016, India. E-mail: sudhanshu@niepa.org.

A new direction for the higher education system in India consists of market-driven transnational provision of education through the mobility of programs and educational institutions. At present this phenomenon is symbolic and market driven, and as yet there is no policy guideline on foreign universities. Given the strong demand for foreign degrees by
Indian students, market-driven trends may dominate in the future. In the absence of government regulation of foreign universities the new trend is posing problems with respect to quality. It increases the risk and uncertainty for the holder of qualification as the recognition of degrees is found to be absent. Moreover, the marketization promotes the commercialization of higher education.

\section{The Presence of Foreign Institutions}

An analysis of the presence of foreign institutions with respect to the country of origin, program types, and modes of operation reveals interesting facts. At present only the United States and the United Kingdom have shown interest in collaborating with Indian partners. Of the I3I institutions in the sample, 59 institutions partnered with UK universities and 66 institutions partnered with US universities. There are other potential countries such as Australia, New Zealand, and Canada that are constantly watching the developments and the government stand on any regulation regarding foreign education providers. At present these countries are organizing educational fairs. They also have representatives to attract Indian students to their respective countries. They lack collaboration with the Indian education system, as they do not find any enabling laws for the legal operation.

Out of the total sample of I3I institutions in India, I07 were providing vocational programs, I9 technical programs, and only 5 general education. In the vocational category, management programs were the most popular. Business management and hotel management constitute approximately 80 percent of the total number of programs. Information shows that Maharashtra has the maximum number of programs in hotel management. Delhi has the maximum number of programs in business management. In technical programs, at present not much interest is shown, although Ig institutions were active in technical sectors as well.

Analysis of 50 institutions shows that the maximum number (30) of programs are offered under twinning arrangements. This is one of the preferred methods for foreign institutions to attract international students to the home country. Twinning is a relatively cheap option, as part of the program is undertaken in the host country. The programmatic collaborations (I8) consist of joint-program and joint-degree provision by the institutions of the home and host countries. Indian partners prefer to design programs with the inputs received from the foreign institution, thereby making the arrangements highly cost competitive. In this mode Indian private partners prefer to collaborate when they get a brand name of a foreign university to award the degree. There are only two franchised institutions in India. There are no offshore campuses in India. The opening of a branch campus requires an investment in terms of infrastructure. Some study centers of UK universities were also found to be operational in India.

Analysis of student perceptions indicates that the practical, market-oriented nature of programs, flexible curricula and 